\title{
ВПЛИВ РІЗНИХ СТРОКІВ ЛІТНЬОГО САДІННЯ СВІЖОЗІБРАНИМИ БУЛЬБАМИ НА ВОДОСПОЖИВАННЯ КАРТОПЛІ В УМОВАХ ЗРОШЕННЯ ПІВДНЯ УКРАЇНИ
}

\author{
ВОЖЕГОВА Р.А. - доктор сільськогосподарських наук, професор, академік \\ Національної академії аграрних наук України \\ https://orcid.org/0000-0002-3895-5633 \\ Інститут зрошуваного землеробства \\ Національної академії аграрних наук України \\ БАЛАШОВА Г.С. - доктор сільськогосподарських наук, \\ старший науковий співробітник \\ https://orcid.org/0000-0001-7023-621X \\ Інститут зрошуваного землеробства Національної академії аграрних наук України \\ БОЯРКІНА Л.В. - кандидат сільськогосподарських наук \\ https://orcid.org/0000-0002-6605-8411 \\ Інститут зрошуваного землеробства Національної академії аграрних наук України \\ САХАЦЬКИЙ Г.І. - кандидат сільськогосподарських наук, доцент \\ https://orcid.org/0000-0002-6763-0846 \\ Державний вищий навчальний заклад «Приазовський державний \\ технічний університет»
}

Постановка проблеми. Вирощування картоплі і використання зрошення - це невід'ємні частини одного цілого, адже здатність коренів картоплі всмоктувати вологу з ґрунту низька, а витрачання вологи культурою дуже високе. Для того щоб утворити один грам сухої речовини, картоплі необхідно у 500-600 разів більше води [9]. За вимогою до вологозабезпечення вегетаційний період картоплі поділяють на три частини: від садіння до початку бутонізації; від початку бутонізації до кінця цвітіння; від кінця цвітіння до збирання врожаю. На першому етапі деяка нестача вологи відіграє навіть позитивну роль, оскільки сприяє росту кореневої системи і проникненню її в глибші шари ґрунту. Найбільш критичним періодом із забезпечення вологи для картоплі $€$ фраза бутонізації-цвітіння, вона співпадає з активним утворенням бульб. Із підвищенням температури зростають і вимоги до умов волого забезпечення, тож у цей період варто особливу увагу приділити питанню забезпечення вологою [4-6; 13; 14]. Отже, виникає необхідність створення оптимальних умов для росту та розвитку рослин картоплі, а також застосування сортів, які б відзначалися пластичністю за настання несприятливих умов та стабільністю високих продуктивних показників [1].

В Інституті зрошуваного землеробства НААН питанням адаптації та розроблення технології вирощування сортів картоплі різних груп стиглості вітчизняної і закордонної селекції, придатних для вирощування двоврожайною культурою в умовах зрошення Півдня України, займаються постійно [2]. Проте є необхідність додатково дослідити питання визначення строків літнього садіння сортів різних груп стиглості в умовах зрошення. Зміни клімату останніми роками спонукають учених-аграріїв до адаптації існуючих, виведення та впровадження у виробництво нових сортів, придатних для вирощування у більш екстремальних умовах [8; 15-17].

Мета статті. Метою проведення досліджень було визначення сумарного водоспоживання та ефективності використання вологи під час вирощування насіннєвої картоплі сортів різних груп стиглості залежно від строків садіння свіжозібраних бульб у літньому садінні.

Матеріали та методика досліджень. Дослідження проводилися на полях Інституту зрошуваного зем- леробства НААН на типовому для Півдня України темно-каштановому ґрунті в умовах зрошення. Під час проведення досліджень та аналізу отриманих результатів керувалися методичними рекомендаціями [5-7; 10; 12]. Для вирішення поставлених завдань у лабораторії біотехнології картоплі І3З НААН у 2014-2015 рр. було проведено двофакторний польовий дослід, який передбачав п'ять строків садіння свіжозібраних бульб супереліти (SE) картоплі сортів різних груп стиглості: ранньостиглої - сорт Щедрик, середньоранньої - сорт Невська та середньостиглої - сорт Слов'янка. Облікова площа ділянки - 6,37 м², густота садіння - 48,3 тис бульб на 1 га, розташування ділянок рендомізоване. Агротехніку у досліді застосовували згідно з розробленими Інститутом зрошуваного землеробства НААН рекомендаціями 3 вирощування картоплі на зрошуваних землях за винятком факторів, що вивчалися [3]. Для визначення достовірності отриманих даних використовували статистичні методи [11].

Результати досліджень. Перший строк садіння проводили 20 червня, решту - через п'ять днів кожен наступний: 25, 30 червня, 5 та 10 липня, згідно зі схемою досліду.

Погодні умови років досліджень були характерними для Півдня України. У 2014 р. за вегетаційний період картоплі літнього строку садіння опади були у вигляді злив, що випадали нерівномірно. Середньомісячна температура повітря за літній період становила $23,5^{\circ} \mathrm{C}$, що на $2,5^{\circ} \mathrm{C}$ вище норми. Максимальний показник температури повітря зафріксували 3 серпня $\left(38,0^{\circ} \mathrm{C}\right)$. Опадів за вегетаційний період літнього садіння випало 102,7 мм (79,2\% від норми), основна частина яких випала в третій декаді червня (22,5 мм), а також у третій декаді липня (19,4 мм). Осінь характеризувалася сухою і теплою погодою. Середньомісячна температура повітря за вересень становила $18,4^{\circ} \mathrm{C}$. Опадів випало 43,0 мм, основна частина яких спостерігалася в третій декаді вересня. На період збирання культури спостерігалася суха, без опадів, погода.

Вегетаційний період картоплі літнього строку садіння 2015 р. був помірно жарким, з опадами у вигляді злив, максимальна кількість опадів (104,6 мм) випала 
у липні. Середньомісячна температура повітря за літній період становила $22,5^{\circ} \mathrm{C}$, що на $1,5^{\circ} \mathrm{C}$ вище норми. Максимальна температура повітря підвищувалася до $38,6^{\circ} \mathrm{C}$ (11 серпня). Осінній період вегетації характеризувалася сухою і теплою погодою. Середньомісячна температура повітря за вересень становила $20,9^{\circ} \mathrm{C}$. Опадів за місяць випало всього 4,6 мм (8 вересня) і до моменту збирання більше не спостерігали.

Водоспоживання картоплі літнього строку садіння змінювалося відповідно до строків садіння свіжозібраних бульб. За садіння 20 червня сумарне водоспоживання становило $2601 \mathrm{~m}^{3} /$ га. За більш пізніх строків садіння вказаний показник зменшувався і мінімальних позначок досягнув за садіння 5 та 10 липня - відповідно 2111 та 2152 м³/га (табл. 1).

Протягом вегетаційного періоду вирощування картоплі дефіцит природного вологозабезпечення мав місце за всіх строків літнього садіння.

Таблиця 1 - Водоспоживання картоплі за різних строків літнього садіння свіжозібраних бульб, середнє за 2014-2015 рр.

\begin{tabular}{|c|c|c|c|c|}
\hline \multirow{2}{*}{$\begin{array}{l}\text { Строк } \\
\text { садіння }\end{array}$} & \multicolumn{3}{|c|}{$\begin{array}{c}\text { Складові сумарного водо- } \\
\text { споживання, м³/га }\end{array}$} & \multirow{2}{*}{$\begin{array}{c}\text { Сумарне } \\
\text { водоспожи- } \\
\text { вання, м³/га }\end{array}$} \\
\hline & опади & \begin{tabular}{|c|} 
ґрунтова \\
волога
\end{tabular} & Поливи & \\
\hline 20 червня & 874 & 102 & 1625 & 2601 \\
\hline 25 червня & 632 & 149 & 1600 & 2380 \\
\hline 30 червня & 481 & 207 & 1550 & 2238 \\
\hline 5 липня & 481 & 180 & 1450 & 2111 \\
\hline 10 липня & 435 & 267 & 1450 & 2152 \\
\hline
\end{tabular}

Баланс водоспоживання забезпечували за рахунок проведення вегетаційних поливів. Найбільше витратили поливної води за строків літнього садіння 30 червня та 5 липня - 69,3\% та 68,7\% відповідно, і хоча значення сумарного водоспоживання (2601 м³/га) $є$ найвищим за першого строку садіння (20 червня), витрати поливної води були менші на 6,2-6,8\% (рис. 1).
Зміни врожайності залежно від строків садіння вплинули на ефективність використання вологи взагалі та зрошувальної води зокрема.

Найбільш економно волога використовувалася у перші два строки садіння - 20 та 25 червня: коесріцієнт водоспоживання становив від 146 до 170 м³/т. За застосування цих строків садіння також найбільш ефективно використовувалася і зрошувальна вода, 1 кубометр якої забезпечував отримання 8,7-10,8 кг продукції. Суттєве погіршення цих показників відбулося за садіння картоплі 5 та 10 липня: на 1 т продукції витрачалося 270-399 м³ вологи, а 1 м³ зрошувальної води забезпечував отримання лише 3,7-5,4 кг бульб (табл. 2).

Таблиця 2 - Ефективність використання вологи за різних строків літнього садіння свіжозібраних бульб сортів різних груп стиглості, середнє за 2014-2015 рр.

\begin{tabular}{|c|c|c|c|c|}
\hline 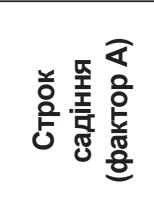 & 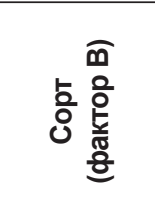 & 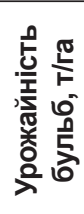 & 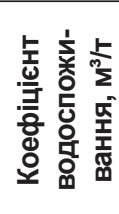 & 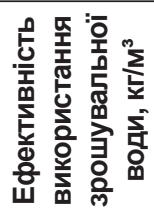 \\
\hline \multirow{3}{*}{20 червня } & Щедрик & 17,40 & 149 & 10,7 \\
\hline & Невська & 16,83 & 155 & 10,4 \\
\hline & Слов'янка & 17,51 & 149 & 10,8 \\
\hline \multirow{3}{*}{25 червня } & Щедрик & 16,25 & 146 & 10,2 \\
\hline & Невська & 13,99 & 170 & 8,7 \\
\hline & Слов'янка & 15,71 & 152 & 9,8 \\
\hline \multirow{3}{*}{30 червня } & Щедрик & 10,17 & 220 & 6,6 \\
\hline & Невська & 11,33 & 198 & 7,3 \\
\hline & Слов'янка & 14,11 & 159 & 9,1 \\
\hline \multirow{3}{*}{5 червня } & Щедрик & 6,79 & 311 & 4,7 \\
\hline & Невська & 7,81 & 270 & 5,4 \\
\hline & Слов'янка & 7,50 & 282 & 5,2 \\
\hline \multirow{3}{*}{10 червня } & Щедрик & 5,39 & 399 & 3,7 \\
\hline & Невська & 6,50 & 331 & 4,5 \\
\hline & Слов'янка & 6,00 & 359 & 4,1 \\
\hline
\end{tabular}

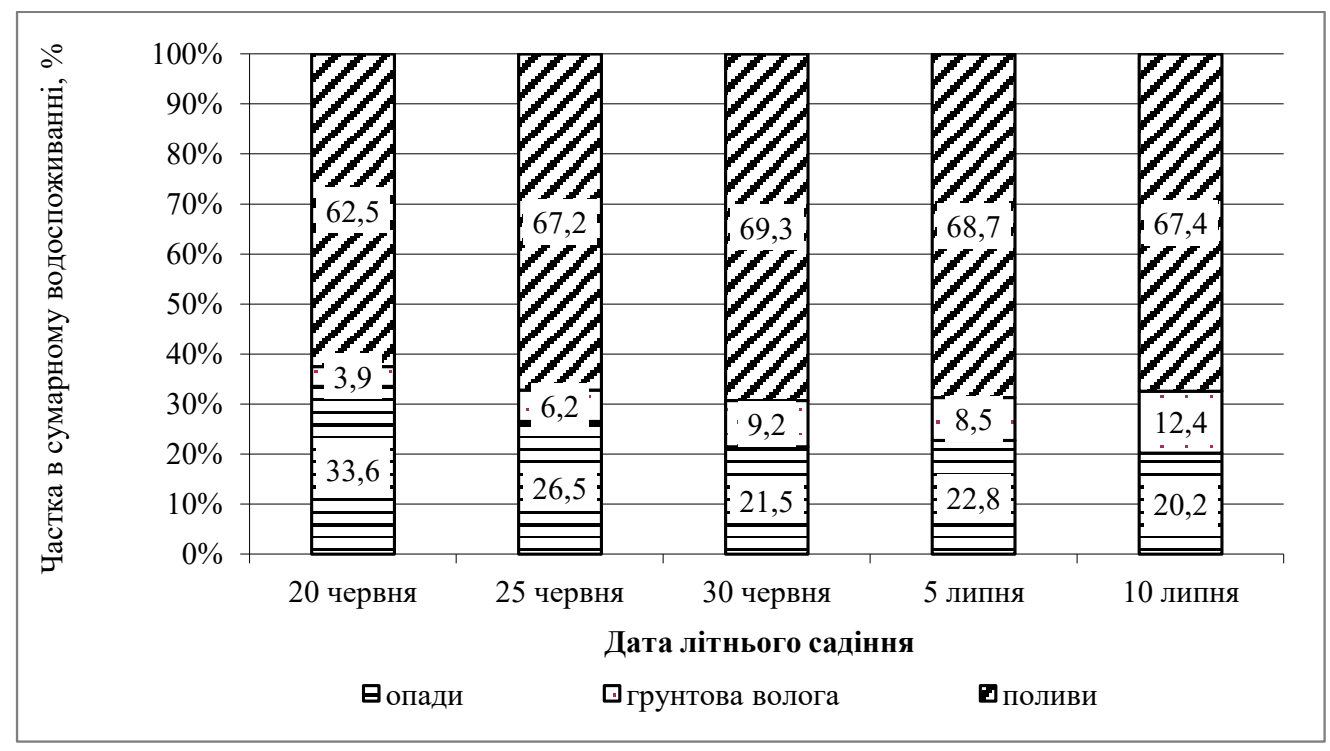

Puс. 1. Структура сумарного водоспоживання картоплі за різних строків літнього садіння свіжозібраними бульбами (середнє за 2014-2015 рр.) 


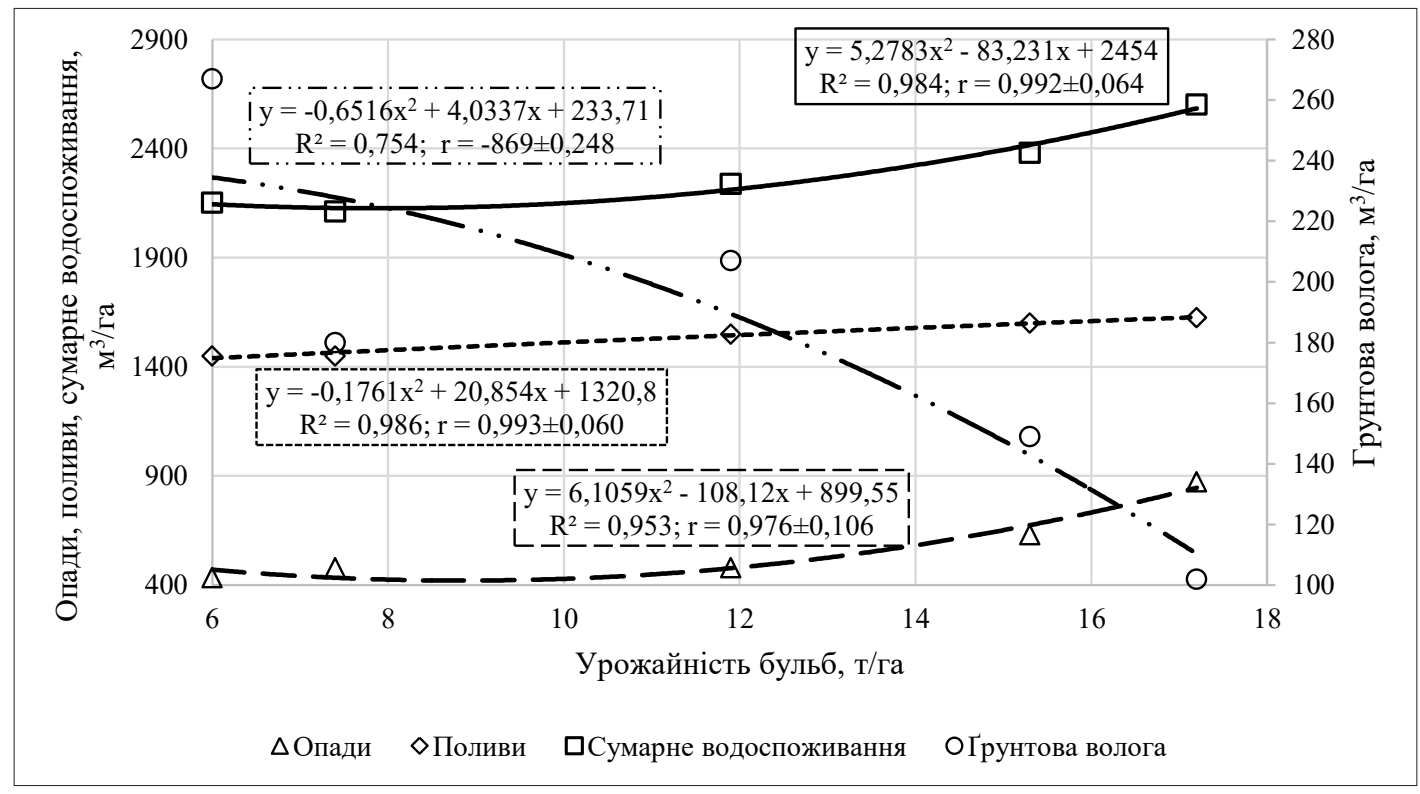

\section{Рис. 2. Поліноміальна модель впливу сумарного водоспоживання та його складників на врожайність бульб}

Варто зауважити, що ефективність використання зрошувальної води сортами різних груп стиглості також відрізнялася. Найвищою вона була у середньостиглого сорту Слов'янка - 7,8 кг/м³ , найнижчою - у ранньостиглого сорту Щедрик $-7,18$ кг/м³.

Результати кореляційно-регресійного аналізу вказують на найвищий ступінь зв'язку між показником урожайності бульб та сумарного водоспоживання $\left(R^{2}=0,984 ; r=0,992 \pm 0,064\right)$. Серед структурних елементів сумарного водоспоживання залежність урожайності бульб від поливів $€$ позитивною і найвищою та дещо нижчою від опадів, розраховані коефіцієнти регресії і детермінації близькі до одиниці: $R^{2}=0,986$; $r=0,993 \pm 0,060$ та $R^{2}=0,953 ; r=0,976 \pm 0,106$ відповідно Нестача ґрунтової вологи призводить до недобору врожаю, на що вказує обернено пропорційний коефіцієнт регресії $(r=-869 \pm 0,248)$ та значно нижчий порівняно з вищеназваними показниками $\left(R^{2}=0,754\right)$ (рис. 2).

Висновки. В умовах Півдня України найбільш економічно виправданим є строк літнього садіння картоплі свіжозібраними бульбами у період із 20 по 25 червня, який забезпечує максимальний рівень врожаю 16,3-17,5 т/га, найбільш економне використання вологи та зрошувальної води (коефіцієнт водоспоживання становив від 146 до 170 м³/т, а 1 кубометр зрошувальної води забезпечував отримання 8,7-10,8 кг продукції).

У подальшому необхідно продовжувати розроблення технологічних прийомів вирощування нових, адаптованих до умов зрошення Півдня України сортів, придатних для вирощування двоврожайною культурою.

\section{СПИСОК ВИКОРИСТАНОЇ ЛІТЕРАТУРИ:}

1. Бугаєва І.П., Сніговий В.С. Культура картоплі на Півдні України. Херсон, 2002. С. 9-10.

2. Бугаєва І.П., Черниченко О.О., Черниченко І.І. Сорти картоплі різних груп стиглості, придатні для вирощування в умовах Півдня двоврожайною культурою. Таврійський науковий вісник. 2007. Вип. 50. С. 59-63.
3. Методика польових і лабораторних досліджень на зрошуваних землях / Р.А. Вожегова та ін. Херсон, 2014. 286 c.

4. Кисляченко М.Ф. Ефективність крапельного зрошення картоплі та овочевих культур в Україні. Продуктивність агропромислового виробництва. Економічні науки. 2014. № 25. С. 102-107. URL: http://nbuv.gov.ua/UJRN/Pav_2014_25_18.

5. Методичні рекомендації щодо проведення досліджень 3 картоплею / В.С. Куценко та ін. ; Ін-т картоплярства. Немішаєве, 2002. 183 с.

6. Наказ Міністерства аграрної політики та продовольства № 384 від 12.07.2019 «Про затвердження Методичних вимог у сорері насінництва щодо збереження сортових та посівних якостей насіннєвої картоплі». URL: https://zakon.rada.gov.ua/laws/show/ z0829-19\#Text.

7. Ромащенко М.І., Шатковський А.П. Тенденції розвитку системи краплинного зрошення. Агробізнес сьогодні. 2014. № 21(292).

8. Ромащенко М.І., Шатковський А.П., Рябков С.В. Краплинне зрошення овочевих культур і картоплі в умовах Степу України. Київ : ДІА, 2012. С. 2-20.

9. Дисперсійний i кореляційний аналіз у землеробстві та рослинництві : навчальний посібник / В.О. Ушкаренко та ін. Херсон : Айлант, 2008. 272 c

10. Статистичний аналіз результатів дослідів у землеробстві / В.О. Ушкаренко та ін. Херсон : Айлант, 2013. 403 c.

11. Методика польового досліду (Зрошуване землеробство) : навчальний посібник / В.О. Ушкаренко та ін. Херсон, 2014. 448 c.

12. AlvaA.K. Water management and water uptake efficiency by potatoes: A review. Agronomy and Soil Science. 2008. № 54:1. DOI:10.1080/03650340701615822.

13. Alva A.K., Moore A.D., Collins H.P. Impact of Deficit Irrigation on Tuber Yield and Quality of Potato Cultivars. Journal of Crop Improvement. 2012. Volume 26. Issue 2. P. 211-227. 
14. Ayyub C.M., Muhammad Wasim Haidar, Faisal Zulfiqar, Zainul Abideen, Shawn R. Wright. Potato tuber yield and quality in response to different nitrogen fertilizer application rates under two split doses in an irrigated sandy loam soil. Journal of Plant Nutrition. 2019. № 42:15. DOI: 10.1080/01904167.2019.1648669.

15. Eskandari A., Khazaie H. R., Nezami A., Kafi M., Majda badi A., Soufizadeh $S$. Effects of drip irrigation regimes on potato tuber yield and quality. Agronomy and Soil Science. 2013. № 59:6. DOI:10.1080/03650340.2012.6 85466.

16. Kawakami J., Iwama K., Jitsuyama Y. Effects of Planting Date on the Growth and Yield of Two Potato Cultivars Grown from Microtubersand Conventional Seed Tubers. Plant Production Science. 2005. № 8:1. P. 74-78. DOI: $10.1626 / p p s .8 .74$.

17. Martin R.J., Jamieson P.D., Wilson D.R. \& Francis G.S. Effects of soil moisture deficits on yield and quality of 'Russet Burbank' potatoes. New Zealand Journal of Crop and Horticultural Science. 1992. № 20:1. DOI: 10.1080/01140671.1992.10422319.

\section{REFERENCES:}

1. Bugaeva, I.P. \& Snehovyi, V.S. (2002). Kultura kartopli na pivdni Ukrayiny [Potato culture in Southern Ukraine]. Kherson [in Ukrainian].

2. Bugaeva, I.P., Chernichenko, O.O. \& Chernichenko, I.I. (2007) Sorty kartopli riznykh hrup styhlosti, prydatni dlya vyroshchuvannya $v$ umovakh pivdnya dvovrozhaynoyu kulturoyu [Potato varieties of different maturity groups, suitable for growing in the south by two-crop]. Tavriyskyy naukovyy visnyk. - Taurian Scientific Bulletin, 50, 59-63 [in Ukrainian].

3. Vozhegova, R.A., Lavrinenko, Yu.O. \& Malyarchuk, M.P. et al. (2014). Metodyka polovykh i laboratornykh doslidzhen na zroshuvanykh zemlyakh [Methods of field and laboratory research on irrigated lands]. Kherson, 286 [in Ukrainian].

4. Kislyachenko, M.F. (2014). Efektyvnist krapelnoho zroshennya kartopli ta ovochevykh kultur $v$ Ukrayini [The effectiveness of drip irrigation of potatoes and vegetables in Ukraine]. Produktyvnist ahropromyslovoho vyrobnytstva. Ekonomichni nauky - Productivity of agroindustrial production. Economic sciences, 25, 102-107. URL: http://nbuv.gov.ua/UJRN/Pav_2014_25_18 [in Ukrainian].

5. Kutsenko, V.S., Osipchuk, A.A. \& Podgayetsky, A.A et al. (2002). Metodychni rekomendatsiyi shchodo provedennya doslidzhen z kartopleyu [Guidelines for conducting research with potatoes]. Nemishayeve, 183 [in Ukrainian].

6. Nakaz Ministerstva ahrarnoyi polityky ta prodovolstva №384 vid 12.07.2019 «Pro zatverdzhennya Metodychnykh vymoh u sferi nasinnytstva shchodo zberezhennya sortovykh ta posivnykh yakostey nasinnyevoyi kartopli» [Order of the Ministry of Agrarian Policy and Food № 384 of 12.07.2019 "On approval of the Methodological requirements in the field of seed production to preserve the varietal and sowing qualities of seed potatoes']. URL: https://zakon.rada.gov.ua/ laws / show / z0829-19 \# Text [in Ukrainian].

7. Romashchenko, M.I. \& Shatkovsky, A.P. (2014). Tendentsiyi rozvytku systemy kraplynnoho zroshennya [Trends in the development of drip irrigation]. Hazeta
"Ahrobiznes sohodni" - The newspaper "Agribusiness Today", 21 (292) [in Ukrainian].

8. Romashchenko, M.I., Shatkovsky, A.P. \& Ryabkov, S.V. (2012). Kraplynne zroshennya ovochevykh kultur $i$ kartopli $v$ umovakh Stepu Ukrayiny [Drip irrigation of vegetable crops and potatoes in the steppe of Ukraine]. Kyiv : DIA [in Ukrainian].

9. Ushkarenko, V.O., Nikishenko, V.L., Goloborodko, S.P. \& Kokovikhin, S.V. (2008). Dyspersiynyy i korelyatsiynyy analiz u zemlerobstvi ta roslynnytstvi : navchalnyy posibnyk [Dispersion and correlation analysis in agriculture and crop production: a textbook]. Kherson : Aylant, 272 [in Ukrainian].

10. Ushkarenko, V.O., Vozhegova, R.A., Goloborodko, S.P. \& Kokovikhin, S.V. (2013). Statystychnyy analiz rezultativ doslidiv $u$ zemlerobstvi [Statistical analysis of experimental results in agriculture]. Kherson : Aylant, 403 [in Ukrainian].

11. Ushkarenko, V.O., Vozhegova, R.A., Goloborodko, S.P. \& Kokovikhin, S.V. (2014). Metodyka polovoho doslidu (Zroshuvane zemlerobstvo) [Methods of field experiment (Irrigated agriculture)]. Kherson, 448 [in Ukrainian].

12. Alva, A.K. (2008). Water management and water uptake efficiency by potatoes: A review. Agronomy and Soil Science. 54:1. Doi:10.1080/03650340701615822 [in English].

13. Alva, A.K., Moore, A.D. \& Collins, H.P. (2012). Impact of Deficit Irrigation on Tuber Yield and Quality of Potato Cultivars. Journal of Crop Improvement. 26(2), 211-227 [in English].

14. Ayyub, C. M., Muhammad, Wasim, Haidar, Faisal, Zulfiqar, Zainul, Abideen \& Shawn, R., Wright (2019). Potato tuber yield and quality in response to different nitrogen fertilizer application rates under two split doses in an irrigated sandy loam soil. Journal of Plant Nutrition. 42:15. DOI: 10.1080/01904167.2019.1648669 [in English].

15. Eskandari, A., Khazaie, H. R., Nezami, A., Kafi, M., Majdabadi, A. \& Soufizadeh, S. (2013). Effects of drip irrigation regimes on potato tuber yield and quality. Agronomy and Soil Science. 59:6. DOI:10.1080/03650 340.2012.685466 [in English].

16. Kawakami, J., Iwama, K. \& Jitsuyama, Y. (2005). Effects of Planting Date on the Growth and Yield of Two Potato Cultivars Grown from Microtubersand Conventional Seed Tubers. Plant Production Science. 8:1, 74-78, DOI: 10.1626/pps.8.74 [in English].

17. Martin, R.J., Jamieson, P.D., Wilson, D.R. \& Francis, G.S. (1992). Effects of soil moisture deficits on yield and quality of 'Russet Burbank' potatoes. New Zealand Journal of Crop and Horticultural Science. 20:1. DOI: 10.1080/01140671.1992.10422319 [in English].

Вожегова Р.А., Балашова Г.С., Бояркіна Л.В., Сахацький Г.І. Вплив різних строків літнього садіння свіжозібраними бульбами на водоспоживання картоплі в умовах зрошення Півдня України

Метою проведення досліджень було визначення сумарного водоспоживання та ефективності використання вологи під час вирощування насіннєвої картоплі сортів різних груп стиглості залежно від строків садіння свіжозібраних бульб в літньому садінні. Матеріали і методи. Дослідження проводилися на 
полях Інституту зрошуваного землеробства НААН на темно-каштановому ґрунті в умовах зрошення протягом 2014-2015 рр. Під час проведення двофракторного польового досліду передбачали п'ять строків садіння свіжозібраних бульб картоплі сортів різних груп стиглості: ранньостиглої - сорт Щедрик, середньоранньої - сорт Невська та середньостиглої - сорт Слов'янка. Облікова площа ділянки - 6,37 м², густота садіння - 48,3 тис бульб на 1 га, розташування ділянок - рендомізоване. Для визначення достовірності отриманих даних використовували статистичні методи. Результати. Протягом вегетаційного періоду вирощування картоплі дефріцит природного вологозабезпечення мав місце за всіх строків літнього садіння. Найбільше витратили поливної води за строків літнього садіння 30 червня та 5 липня $-69,3 \%$ та $68,7 \%$ відповідно, і хоча значення сумарного водоспоживання (2 $601 \mathrm{~m}^{3} /$ га) $є$ найвищим за першого строку садіння (20 червня), витрати поливної води були менші на $6,2-6,8 \%$. Найвищою ефективність водоспоживання

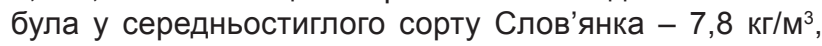
найнижчою - у ранньостиглого сорту Щедрик -

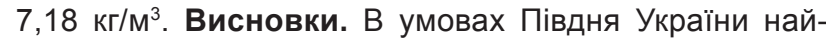
більш економічно виправданим $\epsilon$ строк літнього садіння картоплі свіжозібраними бульбами у період із 20 по 25 червня, який забезпечує максимальний рівень урожаю - 16,3-17,5 т/га, найбільш економне використання вологи та зрошувальної води (коефіцієнт водоспоживання становив від 146 до $170 \mathrm{~m}^{3} / \mathrm{T}$ а 1 кубометр зрошувальної води забезпечував отримання 8,7-10,8 кг продукції).

Ключові слова: картопля, сорт, літнє садіння, дефіцит вологозабезпечення, баланс водоспоживання.

Vozhehova R.A., Balashova H.S., Boyarkina L.V., Sakhatsky G.I. Influence of different terms of summer planting offreshly harvested tubers on waterconsumption of potatoes in the conditions of irrigation of the south of Ukraine

The purpose of the study was to determine the total water consumption and moisture efficiency in the cultivation of seed potatoes of different maturity groups depending on the timing of planting freshly harvested tubers in summer planting. Materials and methods. The research was carried out in the fields of the Institute of Irrigated Agriculture of NAAS on dark chestnut soil under irrigation during 2014-2015. During the twofactor field experiment, five terms of planting freshly harvested potato tubers of different ripeness groups were envisaged: early-ripening - Shchedryk variety, middle-early - Nevska variety and medium-ripe - Slovyanka variety. The estimated area of the plot is $6.37 \mathrm{~m}^{2}$, the planting density is 48.3 thousand tubers per 1 ha, the location of the plots is randomized. Statistical methods were used to determine the reliability of the obtained data. Results and discussion. During the growing season of potato cultivation, the deficit of natural moisture supply took place during all periods of summer planting. Irrigation water was consumed the most during the summer planting periods on June 30 and July $5-69.3$ and $68.7 \%$, respectively, and although the value of total water consumption $\left(2601 \mathrm{~m}^{3} / \mathrm{ha}\right)$ is the highest for the first planting period (June 20), irrigation water consumption were lower by $6.2-6.8 \%$. The highest efficiency of water consumption was in the medium-ripe variety Slovyanka $-7.8 \mathrm{~kg} / \mathrm{m}^{3}$, the lowest - in the early-ripe variety Shchedryk $-7.18 \mathrm{~kg} / \mathrm{m}^{3}$. Conclusion. In the south of Ukraine, the most economically justified is the period of summer planting of potatoes with freshly harvested tubers in the period from 20 to 25 June, which provides a maximum yield of 16.3-17.5 tha, the most economical use of moisture and irrigation water (water consumption was 146 to $170 \mathrm{~m}^{3} / \mathrm{t}$, and 1 cubic meter of irrigation water provided $8.7-10.8 \mathrm{~kg}$ of products).

Key words: potatoes, variety, summer planting, moisture supply, water consumption balance. 